\title{
Coping styles in capital breeders modulate behavioural trade-offs in time allocation: assessing fine-scale activity budgets in lactating grey seals (Halichoerus grypus) using accelerometry and heart rate variability
}

\author{
Courtney R. Shuert ${ }^{1}$ (D) $\cdot$ Patrick P. Pomeroy ${ }^{2}$ (D) $\cdot$ Sean D. Twiss ${ }^{1}$ (D)
}

Received: 25 March 2019 / Revised: 3 December 2019 / Accepted: 12 December 2019 / Published online: 26 December 2019

(C) The Author(s) 2019

\begin{abstract}
Balancing time allocation among competing behaviours is an essential part of energy management for all animals. However, trade-offs in time allocation may vary according to the sex of the individual, their age, and even underlying physiology. During reproduction, higher energetic demands and constrained internal resources place greater demand on optimizing these trade-offs insofar that small adjustments in time-activity may lead to substantial effects on an individual's limited energy budget. The most extreme case is found in animals that undergo capital breeding, where individuals fast for the duration of each reproductive episode. We investigated potential underlying drivers of time-activity and describe aspects of trade-offs in time-activity in a wild, capital breeding pinniped, the grey seal Halichoerus grypus, during the lactation period. For the first time, we were able to access full 24-h activity budgets across the core duration of lactation as well as characterize how aspects of stress-coping styles influence time allocation through the use of animal-borne accelerometers and heart rate monitors in situ. We found that there was a distinct trade-off in time activity between time spent Resting and Alert (vigilance). This trade-off varied with the pup's development, date, and maternal stress-coping style as indicated by a measure of heart rate variability, rMSSD. In contrast, time spent Presenting/ Nursing did not vary across the duration of lactation given the variables tested. We suggest that while mothers balance time spent conserving resources (Resting) against time expending energy (Alert), they are also influenced by the inherent physiological drivers of stress-coping styles.
\end{abstract}

\section{Significance statement}

How animals apportion their time among different behaviours is key to their success. These trade-offs should be finely balanced to avoid unnecessary energy expenditure. Here, we examine how grey seal mothers balance their activity patterns during the short, but energetically demanding, period of pup-rearing. Animal-borne accelerometers provided a uniquely detailed and continuous record of activity during pup-rearing for 38 mothers. We also used heart rate monitors to provide measures of each individual's stress-coping style. We found that mothers balance time Resting against remaining Alert while time Presenting/ Nursing was largely independent of all factors measured. Stress-coping styles were found to drive the balancing and variation of all behaviours. This novel indication that differences in personality-like traits may drive whole activity budgets should be

Communicated by J. Mann

Electronic supplementary material The online version of this article (https://doi.org/10.1007/s00265-019-2783-8) contains supplementary material, which is available to authorized users.

Courtney R. Shuert

cshuert@gmail.com

1 Department of Biosciences, Durham University, Durham DH1 3LE, UK

2 Scottish Oceans Institute, University of St. Andrews, St. Andrews KY16 8LB, UK considered when assessing trade-offs in time allocation across a much wider variety of species.

Keywords Maternal behaviour - Time-activity allocation . Heart rate variability · Pinniped · Lactation · Stress-coping styles

\section{Introduction}

Monitoring changes in fine-scale behaviour is critical to examining trade-offs associated with time allocation. Activity 
budgets are a fixed and finite resource where time spent in one behavioural state automatically creates a rebalancing of the remaining time spent in any other behavioural category. Animals must allocate time among a variety of competing interests and demands across their life-history and have been shown to be driven by a range of intrinsic and extrinsic drivers. Sex-specific and age-specific trade-offs in behaviour have been examined extensively in the literature as they are often associated with demographic variables that are important predictors of population trajectories over time (Loison et al. 1999; Wolf et al. 2005; Byrnes et al. 2011; Hastings et al. 2011; Bishop et al. 2017). Conspecific density also plays an important role in driving a wide variety of behavioural trade-offs and can be key in determining reproductive success in a variety of species (Festa-Bianchet et al. 1998; Horning and Mellish 2012; Maniscalco 2014). Environmental factors, such as thermal regimes, are already known drivers of population-level behavioural trade-offs in a variety of taxa, and have been shown to be strong drivers of individuals balancing thermoregulatory needs with that of other behaviours (Liwanag et al. 2009; Turbill et al. 2011; Paterson et al. 2012; Heerah et al. 2013; Udyawer et al. 2017; Pagano et al. 2018). However, life history requirements may dictate that certain elements of time-activity budgets are less plastic than others.

There has also been a growing interest in how individuals differ in stress management (stress-coping styles) that may dictate an individual's response to competing inputs from the environment, be they natural or anthropogenic stressors (von Borell et al. 2007; Koolhaas et al. 1999, 2011; Schmidt et al. 2010; Liu et al. 2014; Briefer et al. 2015; Pohlin et al. 2017). Individuals have been shown to differ in behavioural responses to stress, ranging from more proactive to more reactive coping styles dependent upon the underlying feedback loops associated with the sympathetic and parasympathetic response pathways (Koolhaas et al. 2010). An individual's position on this pro-reactive spectrum can be characterized by a suite of different heart rate characteristics and behavioural traits (Koolhaas et al. 2011). Changes in short-term heart rate variability, such as rMSSD (root mean square of successive differences in interbeat intervals), can be a good indicator of these stress-coping styles and have been measured in a wide variety of species and contexts (Marchant-Forde et al. 2004; Reefmann et al. 2009; Schmidt et al. 2010; Briefer et al. 2015; Grandi and Ishida 2015). To date, few studies have examined the impact of differences in stress-coping style on how individuals balance time-activity budgets in wild animals (e.g. Závorka et al. 2016). However, an individual's stress coping style is likely to influence the trade-offs that are made within activity budgets in response to other intrinsic or extrinsic drivers.

Typically, time allocation studies utilize visual observation methods, often inferring behaviour for an entire population through intensive scan sampling, but are limited to periods where the individuals of interest are visible (Altmann 1974; Maniscalco et al. 2010; Witter et al. 2012). Recently, accelerometers have allowed collection of remote, fine-scale behaviour free from observer biases (e.g. Naito et al. 2010; Shaffer et al. 2014; Wang et al. 2015), especially relevant for the study of avian and marine mammal behaviour where individuals may remain inaccessible or out of sight much of the time (Goldbogen et al. 2006, 2013; Sakamoto et al. 2009; Stothart et al. 2016). Recording continuously and at high resolution, tri-axial accelerometers can be used to identify changes in body position, dynamic movement patterns, and even changes in affective state (Wilson et al. 2014), even when an animal is outside of its observable period. Collecting behavioural data over a $24-\mathrm{h}$ period for days at a time with the use of accelerometers will overcome the inherent biases associated with traditional observational studies and provide more realistic representations of how individuals balance behavioural trade-offs with respect to intrinsic and extrinsic pressures over time.

Pinnipeds represent an interesting case study for the use of accelerometry to determine fine-scale behavioural trade-offs. Telemetered pinniped research has typically focused on their at-sea behaviour (Biuw et al. 2003; Williams et al. 2004; Skinner et al. 2010; Viviant et al. 2010; Andrews and Enstipp 2016; Jeanniard-du-dot et al. 2017), rather than during the terrestrial phase of pinniped life history including reproduction and nursing. As capital breeding phocids, grey seals (Halichoerus grypus), rely on a fixed reserve of energy stores during their lactation period (Fedak and Anderson 1982; Lydersen and Kovacs 1999; Mellish et al. 1999, 2000). Lactating females must balance behaviours that act towards conserving energy (Resting), transferring resources to her pup (Presenting/Nursing), and remaining vigilant (Alert) to protect her pup which together contribute to defining early pup survival (Hall et al. 2001). Over-expenditure during lactation has costs for the mother (e.g. Pomeroy et al. 1999). Balancing these three behavioural states likely represents a trade-off where too much time spent expending energy by remaining Alert may have a detrimental effect on conserving resources (Resting) and effort towards transferring energy to the pup (Presenting/Nursing). Vigilance (Alert) has already been studied extensively in terrestrial mammals in the context of tradeoffs in time-activity (Caro 1987; Arenz and Leger 1999; Beauchamp 2007; Pangle and Holekamp 2010).

Pinniped mothers are known to respond to a variety of intrinsic and extrinsic pressures, such as exhibiting differential investment of time and internal energetic resources between pup sexes (Anderson and Fedak 1987), pup developmental stages (Fedak and Anderson 1982; Mellish et al. 2000; McDonald and Crocker 2006), and between years with varying favourability of environmental conditions (McMahon et al. 2016; Desprez et al. 2018) which in turn may lead to 
differential survival of offspring (McMahon et al. 2000; Noren 2002; Hastings et al. 2009). Maintaining the high energy throughput associated with capital breeding in grey seal mothers means that optimizing and balancing behaviour and time allocation with the competing demands of intrinsic and extrinsic drivers over time is key for raising a pup without compromising either mother or offspring.

Here, we examine how individual patterns of time allocation, as measured through accelerometry, vary in relation to a range of extrinsic and intrinsic factors, including coping style, with the aim of identifying fundamental trade-offs in time allocation. We focus on three behavioural states (Resting, Alert and Presenting/Nursing) where trade-offs in timeactivity likely exist in lactating grey seals as they make up most of a mother's daily activity budget (typically $>90 \%$ time). Likely extrinsic drivers of behavioural trade-offs include pup sex (Anderson and Fedak 1987), conspecific density (Pomeroy et al. 2000a; Twiss et al. 2003), ambient temperature (Twiss et al. 2002), local topography (access to water; Twiss et al. 2000; Redman et al. 2001; Stewart et al. 2014), and diurnal-nocturnal changes in activity (Culloch et al. 2016; Fraser et al. 2019). Previously, various intrinsic predictors have been found to influence maternal behaviour (maternal mass and length, Pomeroy et al. 1999; phase of lactation and pup developmental stage, Bowen et al. 1992). No study to date has considered intrinsic and extrinsic drivers simultaneously to examine time-allocation trade-offs associated with long-term activity budgets, nor examined the role of individual differences in coping styles in modulating time-allocation patterns in a wild animal. We predict that stress-coping style will be a major determinant of differences in behavioural trade-offs across mothers.

\section{Methods}

\section{Data logger deployments}

Grey seal activity was determined using head-mounted datalogging tri-axial accelerometers (AXY-Depth, Technosmart Europe, Italy) as described in Shuert et al. (2018). Over two consecutive breeding seasons, 38 adult female grey seals were equipped with accelerometers for the core duration of lactation while on land. Adult female grey seals were captured on the Isle of May in Scotland $\left(56.1^{\circ} \mathrm{N}, 2.55^{\circ} \mathrm{W}\right)$ between the months of October and December in 2015 and 2016. Accelerometers were applied during an initial handling event around day 5 of lactation and removed around day 15 , prior to the cessation of lactation. At each handling event, mothers were chemically immobilized via a mass-specific dose of tiletamine-zolazepam ('Zoletil', Virbac, U.K.; see Pomeroy et al. 2000b). Upon sedation, each mother and pup were weighed to the nearest $0.2 \mathrm{~kg}$ using a portable digital scale and tripod as part of a research program on grey seal demography (Pomeroy et al. 1999; Bennett et al. 2007). Accelerometers were housed in custom-designed ballistic nylon pouches attached onto dry pelage using a thin layer of superglue (Loctite, formula 422; Fig. 1) and were configured to sample at $50 \mathrm{~Hz}$ for the 2015 breeding season $\left(n_{\text {ind }}=18\right)$ and $25 \mathrm{~Hz}$ (due to an error in the firmware) during 2016 ( $n$ ind $=20$ ). Seven mothers were sampled in both 2015 and 2016.

As an indicator of stress-coping style we measured resting heart rate variability (HRV; Koolhaas et al. 1999, 2010; von Borell et al. 2007; Coppens et al. 2010; Liu et al. 2014; Briefer et al. 2015) for individual seals. Over the course of accelerometer deployments, study females were also equipped with modified heart rate monitoring activity belts (FirstBeat Technologies Ltd. TM). Each heart rate monitor was placed on the back with the central transmitter housing on the midline with leads extending down both flanks to silver chloride electrodes located immediately posterior to the fore flippers (Fig. 1). A small section of pelage was clipped to match the size of the electrode, held in place by a small plastic donut packed with medical-grade electrogel, and secured with a small cover plate on each donut. The heart rate monitors sample $(1000 \mathrm{~Hz})$ and transmit inter-beat interval data (IBIs, milliseconds) to a portable base station located up to $200 \mathrm{~m}$ from instrumented seals, rather than logging data. While this means that the heart rate data were not sampled continuously over lactation, data were collected over multiple 5-min periods where the animal was at rest for at least $95 \%$ of the $5 \mathrm{~min}$ and not engaged in high-levels of activity during the $5 \mathrm{~min}$. Recordings were made for each individual seal morning and afternoon (daylight hours only) and across the duration of lactation.

Raw IBI values were checked for artefacts using the default options in the Firstbeat ${ }^{\mathrm{TM}}$ Sports software (v. 4.5.0.2) installed on the receiver station, which automatically corrected potentially missing beats (extreme long IBIs) by interpolation, and deleted spurious extra beats (extreme short IBIs; Sami et al.

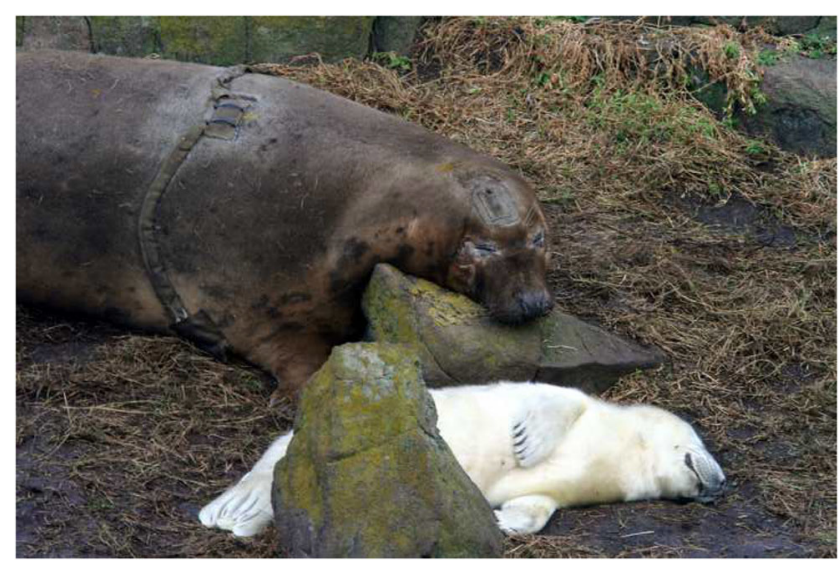

Fig. 1 Example showing placement of head-mounted accelerometers and heart rate monitor on a study female with her pup in view 
2004). Corrected IBI data were also compared to 1 min duration ECG data for 12 individuals and was found to be highly accurate (mean difference between Firstbeat ${ }^{\mathrm{TM}}$ IBI data and ECG measurements was $0.87 \pm 0.16 \mathrm{~ms}$; SDT, unpublished data). In addition, we filtered IBI data further by identifying invariable sequences of IBIs (two or more consecutive identical inter-beat intervals; flats) or monotonically changing IBIs (two or more identical non-zero changes in IBIs; stairs) using custom R scripts. Only those 5-min traces with less than 50\% of these flats and stairs were included in subsequent analyses (2015: mean traces per seal $( \pm$ standard error, $S E)=24 \pm 6$; 2016: mean traces per seal $=37 \pm 7$ ). We computed the root mean square of successive differences in inter-beat-intervals (rMSSD; ms) for each of these $5 \mathrm{~min}$ traces using the R package 'RHRV' (Rodriguez-Linares et al. 2017). We used the median rMSSD for each individual across the entire season as our measure of resting HRV to assess whether stress-coping styles would have any influence over time-activity budgets.

\section{Accelerometer-derived activity budgets}

Accelerometer data were transformed and summarized by 33 feature variables that characterize various elements of static and dynamic acceleration, corresponding to body position and movement, respectively, as well as elements of power spectrum density and frequency within the signal (Shuert et al. 2018). These variables were used to classify the entirety of the accelerometry data for the duration of the deployed time for each individual into 6 behavioural states at the resolution of 1-s. The behavioural states included were Resting, Alert, Flippering pup, Locomotion, Presenting/Nursing, and Comfort Movements. Video footage was used to label accelerometry data to train a random forest model that was then used to classify each female's activity budget as detailed in Shuert et al. (2018). It was not possible to record data blind because our study involved focal animals in the field. For the purposes of this study, we focus on three of these behaviours that make up the greater part (>90\%) of a female's activity budget during lactation and are therefore more likely to exhibit trade-offs in time-activity allocation; Resting, Alert, and Presenting/Nursing (Table 1). It should be noted that these are behavioural categories determined exclusively from accelerometry data and do not provide information on the location of a female's pup nor any other contextual information that might be typically found in an ethological study. Therefore, the behaviour Presenting/Nursing represents a specific body position which we associate with nursing effort on the part of the grey seal mother (see Table 1), rather than a discrete measure of milk transfer or interaction with a pup. Activity budgets were summarized by consecutive day and night period, split by the timing of civil twilight in order to match previous efforts to study activity (e.g. Murie and Lavigne 1991; Harris et al. 2001; Culloch et al. 2016); day light hours included civil twilight at both ends of what constituted a day.

\section{Factors influencing behaviour and model parameterization}

Predictors of time spent in each of the three key behavioural states (Resting, Alert, and Presenting/Nursing) were modelled separately using binomial GLMMs with a logit link function. Predictors were included as fixed-effects and were classified as either intrinsic to each female-pup pair or extrinsic variables acting upon each female-pup pair. As target mother arrival on the colony was closely monitored, the parturition date for our study females in each breeding season was estimated to within a day and therefore allowed for an estimate of maternal postpartum mass. Intrinsic fixed effects included initial mother post-partum mass as an indicator of size and condition, the stage of the pup on a given day (classed as stage I to IV according to Kovacs and Lavigne 1986; Woldstad and Jenssen 1999), pup sex, and the phase of lactation (Lphase) split into three phases (early: 1-6 days, mid: 7-10 days, late: $11+$ days post-partum). Each mother's resting heart rate variability (rMSSD) was also included as an intrinsic variable to evaluate the influence of stress-coping style on whole activity budgets (Coppens et al. 2010; Monestier et al. 2015). Weather variables were collected continuously across each breeding season from a weather station located in the centre of the island (Supplemental Fig. 1). For the purposes of this analysis, extrinsic fixed effects included daily maximum temperature
Table 1 Description of behaviour states for assessing time trade-offs in lactating female grey seals, a summary of static heave acceleration (stZ; median with 1 st and 3rd quartile in brackets) found to be the most important variable for classifying behaviour in head-mounted accelerometers, as well as the mean proportion $( \pm$ SD) of time spent in each behavioural state across deployments as classified through accelerometry (behaviour definitions and acceleration summary adapted from Shuert et al. 2018)

\begin{tabular}{llll}
\hline Behaviour & Description & Accel. (stZ) & Prop. \\
\hline Resting & Seal is motionless, head on ground & $0.720(0.044,0.836)$ & $0.607 \pm 0.11$ \\
Alert & Seal is stationary, head is up and moving, may look at pup & $0.817(0.722,0.878)$ & $0.303 \pm 0.11$ \\
Presenting/Nursing & Seal is rolled laterally so that nipples are presented to pup & $0.173(-0.228,0.711)$ & $0.051 \pm 0.05$ \\
\hline
\end{tabular}


(DMT), daily mean wind speed (Mwind), and total daily precipitation (Precip). We included date, modelled as a polynomial of days since October 1st, to represent seasonal changes in colony density which roughly follows a negative second order polynomial pattern, with the highest density mid-way through the season. Grey seal mothers remain with their pup throughout lactation and occupy a relatively small area (typically ranging no more than c. $20 \mathrm{~m}$ from their birth site; Pomeroy et al. 2000b). Therefore, we recorded each mother's locations within the colony, based on 7 geographic regions on the island that seals use (see definitions in Supplemental Fig. 1) to represent gross differences in colony topography and access to water.

A preliminary analysis found that the behavioural data were overdispersed. Mother identity was included as a random effect in all models to not only account for overdispersion, but also to account for individual variability in behaviour (Bolker et al. 2009). Behavioural data were modelled as the proportion of time spent in the behaviour of interest, weighted appropriately for the total number of seconds in each day and night period from the accelerometer data, as each day of the study lost about 5 min of daylight. As this was the first opportunity to access the full suite of night behaviour, the proportion of time spent in each behaviour was parameterized for each consecutive day and night $(\mathrm{dn})$ for the length of each deployment with dn included as a factor in all models. Intrinsic and extrinsic models were designed a priori and are listed in Table 2 ( $\mathrm{a}$ and $\mathrm{b}$ ). Pup sex was included in all models as it has already been shown to influence how a grey seal mother partitions her time (Anderson and Fedak 1987; Kovacs 1987). As a result, our null models presented here include pup sex and dn to capture what is already known to influence activity budgets in grey seal mothers.

Candidate models were ranked based on Akaike information criterion, corrected for small sample size (AICc; Anderson et al. 1998) and model deviance. Models were initially designed in two different groups including intrinsic factors and extrinsic factors separately. This was done in order to tease apart the potential trade-offs associated with separate influences of potential intrinsic or extrinsic drivers of behaviour, without masking any important factors that may be lost within model selection methods. Top models were selected using AICc model selection methods (Burnham and Anderson 2002). Those factors included within 2 delta AICc were considered to have extensive support in modelling, while those with $\leq 5$ delta AICc were considered to have minor support. Models with more than 7 delta $\mathrm{AICc}$ were not considered further (Burnham and Anderson 2002; Burnham et al. 2011). Model covariates with extensive or minor support from each of the two model groups (intrinsic, extrinsic) were combined into a reduced model list with the heart rate
Table 2 Initial predictors for generalized linear mixed effects models (GLMM) including (a) intrinsic variables and (b) extrinsic variables used to assess time spent Resting, Alert, and Presenting/Nursing with female ID included as a random factor. Intrinsic predictors include the phase of lactation (Lphase), date (modelled as a second-order polynomial), and pup stage. Maternal size was characterized by estimated maternal postpartum mass (MPPM). Extrinsic predictors include daily maximum temperature (DMT), mean wind speed (Mwind), total daily precipitation (Precip), date, and colony location. All models included pup sex and day/night (dn), including the null. Following initial reduction, rMSSD was added to models with extensive and minor support

\begin{tabular}{|c|c|c|}
\hline & No. & Binomial GLMM predictors \\
\hline \multirow[t]{8}{*}{ (a) Intrinsic models } & 1 & $\begin{array}{l}\text { Lphase + Date }{ }^{*}+\text { PupStage } \\
+ \text { PupSex + MPPM + dn }\end{array}$ \\
\hline & 2 & $\begin{array}{l}\text { Date }^{*}+\text { PupStage + PupSex } \\
\quad+\text { MPPM + dn }\end{array}$ \\
\hline & 3 & $\begin{array}{l}\text { Lphase }+ \text { PupStage }+ \text { PupSex } \\
+ \text { MPPM }+ \text { dn }\end{array}$ \\
\hline & 4 & Date $^{*}+$ PupSex + MPPM + dn \\
\hline & 5 & Lphase + PupSex + MPPM + dn \\
\hline & 6 & PupStage + PupSex + MPPM + dn \\
\hline & 7 & PupStage + PupSex + dn \\
\hline & 8 & PupSex + dn (null) \\
\hline \multirow[t]{11}{*}{ (b) Extrinsic models } & 1 & $\begin{array}{l}\text { DMT + Mwind + Precip + Date } \\
+ \text { + ColLoc + PupSex + dn }\end{array}$ \\
\hline & 2 & $\begin{array}{l}\text { DMT + Precip + } \text { Date }^{*}+\text { ColLoc } \\
\quad+\text { PupSex }+ \text { dn }\end{array}$ \\
\hline & 3 & $\begin{array}{l}\text { DMT + Mwind + Date }{ }^{*}+\text { ColLoc } \\
\quad+\text { PupSex }+ \text { dn }\end{array}$ \\
\hline & 4 & DMT + ColLoc + PupSex + dn \\
\hline & 5 & Precip + ColLoc + PupSex + dn \\
\hline & 6 & Mwind + ColLoc + PupSex + dn \\
\hline & 7 & ColLoc + PupSex + dn \\
\hline & 8 & $\mathrm{DMT}+$ PupSex $+\mathrm{dn}$ \\
\hline & 9 & Mwind + PupSex + dn \\
\hline & 10 & Precip + PupSex + dn \\
\hline & 11 & PupSex + dn (null) \\
\hline
\end{tabular}

All continuous variables were scaled and centred to meet model assumptions

* Date modelled as a second-order polynomial

variability metric, rMSSD, and competed against the null for each of the three behavioural states to identify potential trade-offs in time allocation and the respective drivers of those trade-offs (Burnham et al. 2011). Selected models were described by their deviance and Akaike weight and relative evidence ratios, calculated as the ratio of model weight between two models of interest (Burnham and Anderson 2002; Burnham et al. 2011). All models were built using the 'glmmTMB' package, ranked using the 'bbmle' package, and covariates model averaged with the 'MuMIn' package in $\mathrm{R}$ (version 3.5.0; Bolker and Team 2017; Magnusson et al. 2017; Barton 2018). 


\section{Results}

\section{Resting}

A post hoc analysis of intrinsic and extrinsic models found that grey seal mother size and all weather variables were likely 'pretending variables', as they failed to reduce model deviance compared to those models that did not include each of these factors (Anderson 2008; Burnham et al. 2011). As a result, models including these factors were removed from model competition for time spent Resting (see Supplementary Table 1). Model weights were recomputed after the removal of pretending and unsupported variables. Minor support $(\leq 5$ delta $\mathrm{AICc}$ ) was found for the inclusion of pup stage as a predictor of time spent Resting in addition to the inclusion of pup sex and the effects of day and night (dn; Table 3(A)). Compared to the average across all pup stages, mothers with stage II pups rested significantly longer (Wilcoxon rank sum; $W=15,146, p<0.001)$, while mothers with pups at stage IV rested significantly less ( $W=35,062, p=0.006$; Fig. 2). Mothers also spent significantly less time resting with female

Table 3 Final models for predicting time spent (A) Resting, (B) Alert, and (C) Presenting/Nursing in lactating female grey seals with extensive and minor support, following the removal of several pretending variables as determined by a post hoc analysis. Models were ranked based on Akaike information criterion, corrected for small sample size (AICc). pups $(W=57,330, p=0.006)$ and rested significantly more at night ( $W=28,550, p<0.001$; Table 4$)$. Little to no support was found for more complicated models including colony location or other intrinsic variables, with the exception of date. Time spent Resting was highest at the start and end of the season, as indicated by positive relationship for the parabolic effect of our date variable (Table 4).

Extensive support was found for the effect of resting HRV (rMSSD; $\leq 2$ delta AICc, Table 3(A), Supplementary Table 1) compared to models without this variable, yielding a combined evidence ratio of 5.6 above the models that omitted rMSSD, and holding $69 \%$ of the model weight (Table 3(A)). Grey seal mothers with higher rMSSD tended to rest for longer than those with lower HRV, with an apparent inflexion point in the sigmoid-like relationship at around $55 \mathrm{~ms}$ (Fig. 3a, Table 4). The combined evidence ratio for the inclusion of rMSSD along with pup stage and date was 11.7 above the null model (pup sex and dn only; Table 3A). Final models, rankings, and recomputed Akaike weights are included in Table 3A. Variable estimates were model-averaged across these final top models (Table 4).
Time spent Resting and Alert were best described by pup stage, date (* modeled as a second order polynomial), and the heart rate variability metric rMSSD. Time spent Presenting/Nursing was best described by location on the colony and rMSSD. Pup sex and differences in day and night activity $(\mathrm{dn})$ were included in every model

\begin{tabular}{|c|c|c|c|c|}
\hline Model formula & $k$ & Delta AICc & Weight & Deviance \\
\hline \multicolumn{5}{|l|}{ (A) Resting } \\
\hline Date $^{*}+$ PupStage + rMSSD + PupSex + dn & 8 & 0.0 & 0.410 & 1367.099 \\
\hline PupStage + rMSSD + PupSex $+d n$ & 6 & 2.0 & 0.149 & 1373.224 \\
\hline rMSSD + PupSex + dn & 5 & 2.3 & 0.131 & 1375.521 \\
\hline Date $*+$ PupStage + PupSex + dn & 7 & 2.4 & 0.123 & 1371.555 \\
\hline Date $^{*}+$ PupSex + dn & 6 & 2.6 & 0.111 & 1373.815 \\
\hline PupStage + PupSex + dn & 5 & 4.6 & 0.042 & 1377.810 \\
\hline PupSex + dn (null) & 4 & 4.9 & 0.035 & 1380.179 \\
\hline \multicolumn{5}{|l|}{ (B) Alert } \\
\hline Date $^{*}+$ rMSSD + PupSex + dn & 7 & 0.0 & 0.401 & 1304.548 \\
\hline Date $^{*}+$ PupStage + rMSSD + PupSex + dn & 8 & 0.3 & 0.344 & 1302.803 \\
\hline rMSSD + PupSex + dn & 5 & 3.3 & 0.079 & 1311.888 \\
\hline Date* + PupSex + dn & 6 & 3.5 & 0.069 & 1310.115 \\
\hline PupStage + rMSSD + PupSex + dn & 6 & 4.3 & 0.046 & 1310.908 \\
\hline Date $*$ PupStage + PupSex + dn & 7 & 4.5 & 0.043 & 1309.020 \\
\hline PupSex + dn (null) & 4 & 7.1 & 0.012 & 1317.758 \\
\hline PupStage + PupSex + dn & 5 & 8.1 & 0.007 & 1316.715 \\
\hline \multicolumn{5}{|l|}{ (C) Presenting/Nursing } \\
\hline PupSex + dn (null) & 4 & 0.0 & 0.440 & 587.326 \\
\hline ColLoc + rMSSD + PupSex + dn & 11 & 1.4 & 0.220 & 574.359 \\
\hline rMSSD + PupSex + dn & 5 & 1.6 & 0.190 & 586.933 \\
\hline MPPM + ColLoc + rMSSD + PupSex + dn & 12 & 7.1 & 0.150 & 573.090 \\
\hline
\end{tabular}




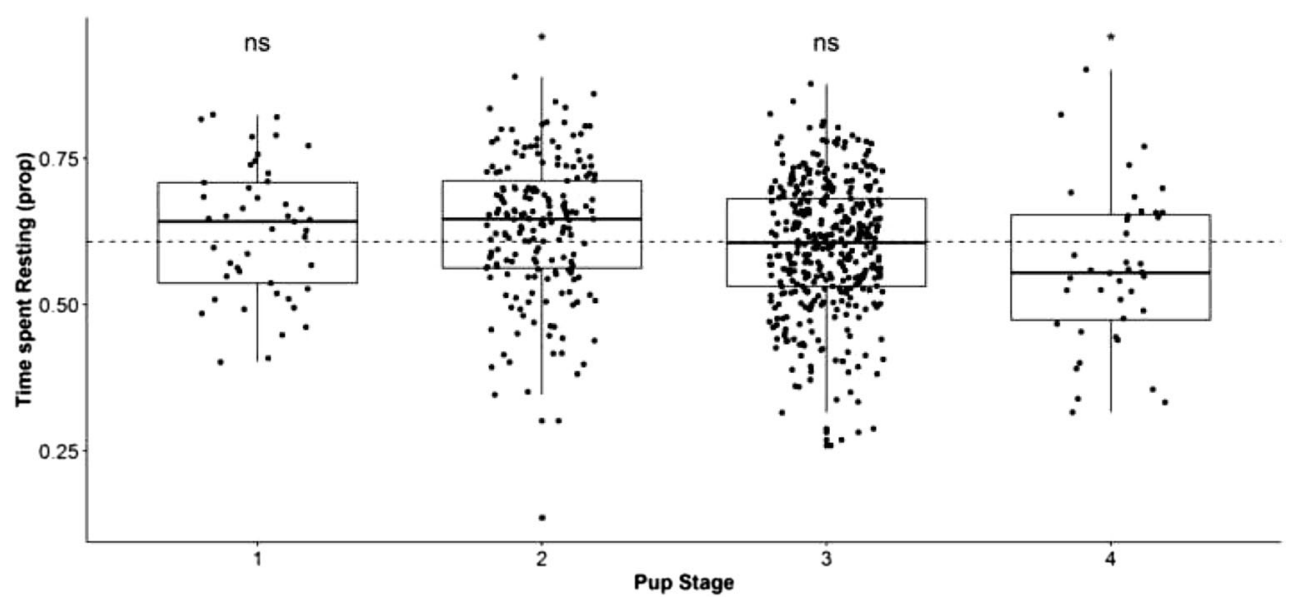

Fig. 2 Boxplot of time spent resting as a function of pup stage in grey seals. The boxes show the median, interquartile range, whiskers (indicating the 90th and 10th percentiles), and individual data points. Grey seal mothers spent significantly longer Resting when pups were

\section{Alert}

As with models predicting time spent Resting, time spent Alert was best explained by a model including date, pup stage, and rMSSD following the elimination of variables in the post hoc reduction from the larger pool of models (Supplementary Table 2), carrying $34.4 \%$ of the total model weight. Minor support ( $\leq 5$ delta AICc) was identified for less complicated models including these variables, but the full model still had an evidence ratio of 4.354 above the next best model and 28.667 above the null (Table 3(B)).

Grey seal mothers with a lower resting HRV (lower rMSSD) spent a greater portion of their time Alert than those with a more variable heart rate (Fig. 3b), with an apparent inflection point of the sigmoid-like relationship again at around $55 \mathrm{~ms}$. Mothers spent significantly more time alert with female pups than male pups (Wilcoxon rank sum; W = $43,820, p=0.002$; Table 5). Grey seal mothers also spent significantly less time Alert at night $(W=74,664, p<0.001$; Table 5). Mothers spent significantly less time Alert during stage II of pup development than the overall mean ( $W=$ $49,104, p=0.001$ ) and a significantly longer time alert in stage IV ( $W=8946.5, p=0.006$; Fig. 4). As with Resting, time spent Alert was found to be influenced by the effect of date, where Alert was found to be highest at the mid-point of the season as indicated by the negative beta parameter for both terms of the polynomial relationship (Table 5). Beta estimates for top models predicting time spent Alert were model averaged across all top models and can be found in Table 5 .

\section{Presenting/Nursing}

Extensive support was found for the inclusion of colony location and rMSSD, in addition to the mandatory inclusion of stage II than average (dashed line), and significantly less in stage IV, as indicated by the $(*)$ above each boxplot. Stage I and III were not significantly different than average (ns). Significance was determined using Wilcoxon rank sum tests

pup sex and dn, in our models of time spent Presenting/ Nursing (Supplementary Table 3). However, these models were equivalent in predictive power to that of the null model (Table 3(C)), and therefore must be regarded with caution. No support was found for any other intrinsic or extrinsic model variables, with the exception of maternal post-partum mass (MPPM), in predicting time spent Presenting/Nursing, though MPPM did not have any support in the final model table ( $>7$ delta AICc; Table 3(C)). All models equivalent to those listed in Table 3(C) but without rMSSD were found to have no support in final models and were ultimately removed ( $>7$ delta AICc).

There was no significant difference between time spent Presenting/Nursing male and female pups (Wilcoxon rank

Table 4 Model-averaged variable estimates of top binomial GLMMs describing time spent Resting in lactating grey seals. Top model predictors included date (modelled as a second-order polynomial), pup stage (against stage II), and rMSSD with pup sex (positive condition is female) and day vs. night (dn; positive condition is night) included in all models. In order to meet model assumptions, rMSSD was scaled and centred

\begin{tabular}{lllll}
\hline Variable & Estimate & Std. error & \multicolumn{2}{l}{$95 \%$ confidence } \\
\cline { 3 - 5 } & & & Upper & Lower \\
\hline (Intercept) & 0.513 & 0.196 & 0.897 & 0.128 \\
Date-poly 1 & 0.045 & 0.049 & 0.141 & -0.051 \\
Date-poly 2 & 0.046 & 0.049 & 0.142 & -0.050 \\
PupStage & -0.070 & 0.067 & 0.061 & -0.201 \\
rMSSD* & 0.059 & 0.051 & 0.158 & -0.040 \\
PupSex (F) & -0.138 & 0.084 & 0.026 & -0.302 \\
dn (night) & 0.371 & 0.078 & 0.523 & 0.218 \\
\hline
\end{tabular}

*Scaled and centred 

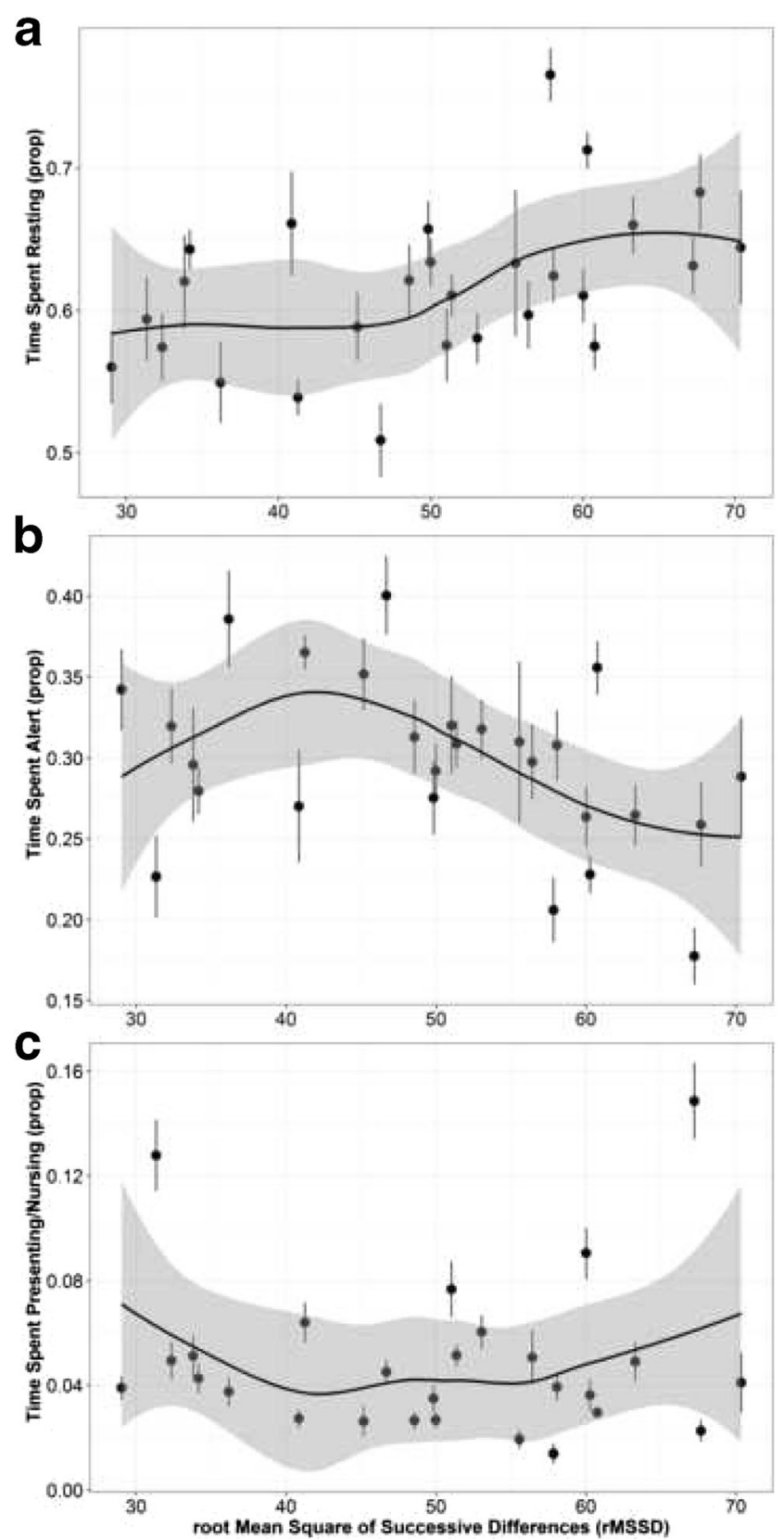

Fig. 3 Scatter plot of time spent (a) Resting, (b) Alert, and (c) Presenting/ Nursing as a function of the root mean square of successive differences (rMSSD; ms) describing resting heart rate variability in grey seal mothers. Point values represent the mean time spent in each behaviour by each female, with standard error represented by the black bars around each point. The solid line represents a loess-smoothed trend line with $95 \%$ confidence intervals around the line in grey

sum; $W=53,655, p=0.252)$, but mothers tended to spend significantly more time Presenting/Nursing at night ( $W=$ 46,121, $p=0.019$; Table 6). While there was variability in the response of time spent Presenting/Nursing in relation to rMSSD, the relationship appears mostly flat (Fig. 3c). Presenting/Nursing time varied significantly across the seven colony locations (Kruskal-Wallis rank sum $=92.634$, $p<0.001$; Fig. 5). Grey seal mothers in Karen's Gully (KG) and the Loan Road (LR), areas with access to freshwater pools, had the highest average time Presenting/Nursing, while those in Cross Park (XP), an area with no freshwater access, had the lowest average time Presenting/Nursing (Fig. 5). Beta parameter estimates were model averaged for top model variables of time spent Presenting/Nursing and can be found in Table 6.

\section{Discussion}

Grey seal maternal behaviour over a continuous multi-day period during lactation was analysed using accelerometry data, focusing on three core behaviours that constitute over $90 \%$ of a typical activity budget. Overall, it was found that time spent both Resting and Alert by grey seal mothers were best explained by complimentary models including the effect of a pup's developmental stage, the influence of time as expressed through the polynomial variable of date, and the mother's resting HRV (rMSSD). Significant differences were also found between pup sexes as well as difference between day and night periods with respect to these two behaviours. Time spent Presenting/Nursing, on the other hand, was found to be relatively constant across coping styles over lactation, though all final models were equal in predictive power to that of the null model. Mothers of male or female pups did not differ in time spent Presenting/Nursing, though they did allocate more time to this activity overnight. Colony location also influenced time spent Presenting/Nursing, indicating that topographical features, such as access to freshwater pools, may drive behaviour.

Table 5 Model averaged variable estimates of top binomial GLMMs describing time spent Alert in lactating grey seals. Top model predictors included date (modelled as a second-order polynomial), pup stage (against stage II), and rMSSD with pup sex (positive condition is female) and day vs. night (dn; positive condition is night) included in all models. In order to meet model assumptions, rMSSD was scaled and centered

\begin{tabular}{lrrrr}
\hline Variable & Estimate & Std. error & \multicolumn{2}{c}{$95 \%$ confidence } \\
\cline { 3 - 5 } & & & Upper & Lower \\
\hline (Intercept) & -0.816 & 0.175 & -0.473 & -1.159 \\
Date-poly 1 & -2.060 & 1.439 & 0.760 & -4.880 \\
Date-poly 2 & -1.932 & 1.390 & 0.792 & -4.656 \\
PupStage & 0.035 & 0.058 & 0.148 & -0.078 \\
rMSSD* & -0.090 & 0.052 & 0.011 & -0.191 \\
PupSex (F) & 0.190 & 0.089 & 0.365 & 0.015 \\
dn (night) & -0.427 & 0.083 & -0.264 & -0.589 \\
\hline
\end{tabular}

*Scaled and centred 


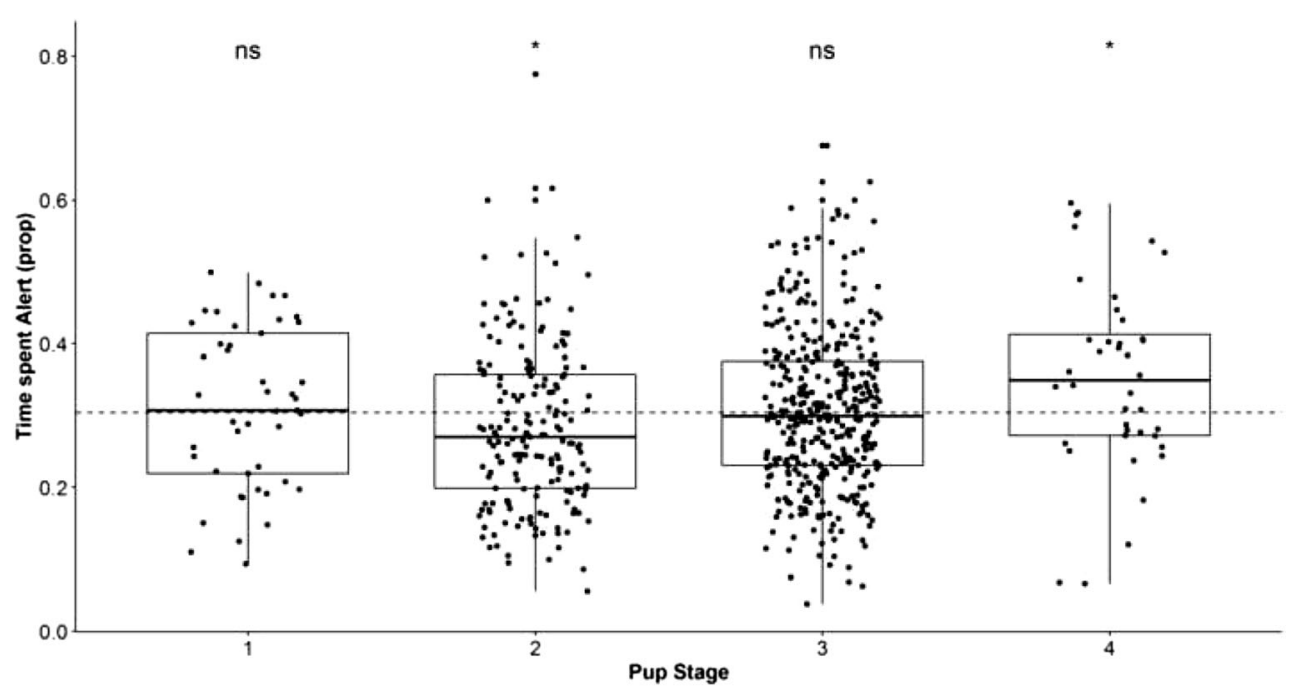

Fig. 4 Boxplot of time spent Alert as a function of pup developmental stage. The boxes show the median, interquartile range, whiskers (indicating the 90th and 10th percentiles), and individual data points. The dashed horizontal line represents the grand mean of time spent Alert. Grey seal mothers spent significantly less than average time Alert when pups were in stage II, while spending more time Alert late in lactation when pups were at stage IV, as indicated by the $(*)$ above each boxplot. Stages I and III were not significantly different than average (ns). Significance was determined using Wilcoxon rank sum tests

threats (Pomeroy et al. 2000a; Twiss et al. 2003). Mothers were found to spend significantly more time Resting and less time Alert with pups in developmental stage II, while the opposite was found for pups in developmental stage IV as they approached weaning. During the early stages of development, pups are generally fairly immobile and do not tend to stray far from their mothers (Kovacs 1987). Milk fat content peaks from remaining vigilant, such as aggression or fleeing. Time spent Resting and Alert appear to represent a key trade-off in grey seal mothers; both behaviours were best predicted by identical model variables with opposing effects. The resulting relationships indicate that these two behaviours are complimentary with regard to the sex of a pup, its developmental stage, time, and the mother's resting HRV. Given the evidence presented here, we argue that a trade-off in the conservation of internal resources through Resting and appropriately expending energy while Alert represents a key trade-off in time allocation over the course of lactation for grey seals.

Interestingly, these two behaviours appeared to be subject to the changing density across the colony, as indicated by the opposing relationships between date for Resting and Alert. The Isle of May birth curve, and therefore number of seals ashore, like many other breeding rookeries follows a normal distribution with a peak in density towards the middle of the season around mid-November (Pomeroy et al. 2000a, b; Hall et al. 2001). While we do not have daily estimates of colony density across the study period, the results with respect to trading off time spent Resting and Alert respond as one might expect. Grey seal mothers spent more time Alert and less time Resting mid-season when colony density is highest. Grey seals mothers, at higher densities, must remain vigilant to keep track of and protect their pups from conspecifics and other
Table 6 Model-averaged variable estimates of top binomial GLMMs describing time spent Presenting/Nursing in lactating grey seals. Top models included the effect of colony location (ColLoc against KG, sublocation codes can be found in Fig. 5 and Supplemental Fig. 1) and rMSSD as well as pup sex (positive condition is female) and day vs. night

\begin{tabular}{lllll}
\hline Variable & Estimate & Std. error & \multicolumn{2}{l}{$95 \%$ confidence } \\
\cline { 4 - 5 } & & & Upper & Lower \\
\hline (Intercept) & -2.832 & 0.416 & -2.016 & -3.647 \\
ColLoc: LR & 0.155 & 0.392 & 0.923 & -0.613 \\
ColLoc: RT & -0.261 & 0.460 & 0.640 & -1.162 \\
ColLoc: TC & -0.299 & 0.524 & 0.728 & -1.326 \\
ColLoc: TH & -0.104 & 0.298 & 0.480 & -0.688 \\
ColLoc: XP & -0.346 & 0.530 & 0.692 & -1.384 \\
ColLoc: CH & -0.371 & 0.646 & 0.895 & -1.637 \\
rMSSD* & 0.079 & 0.113 & 0.300 & -0.181 \\
PupSex (F) & -0.030 & 0.212 & 0.385 & -0.445 \\
dn (night) & 0.099 & 0.173 & 0.438 & -0.240 \\
\hline
\end{tabular}

*Scaled and centred (dn, positive condition is night) included in all models. In order to meet model assumptions, rMSSD was scaled and centred 


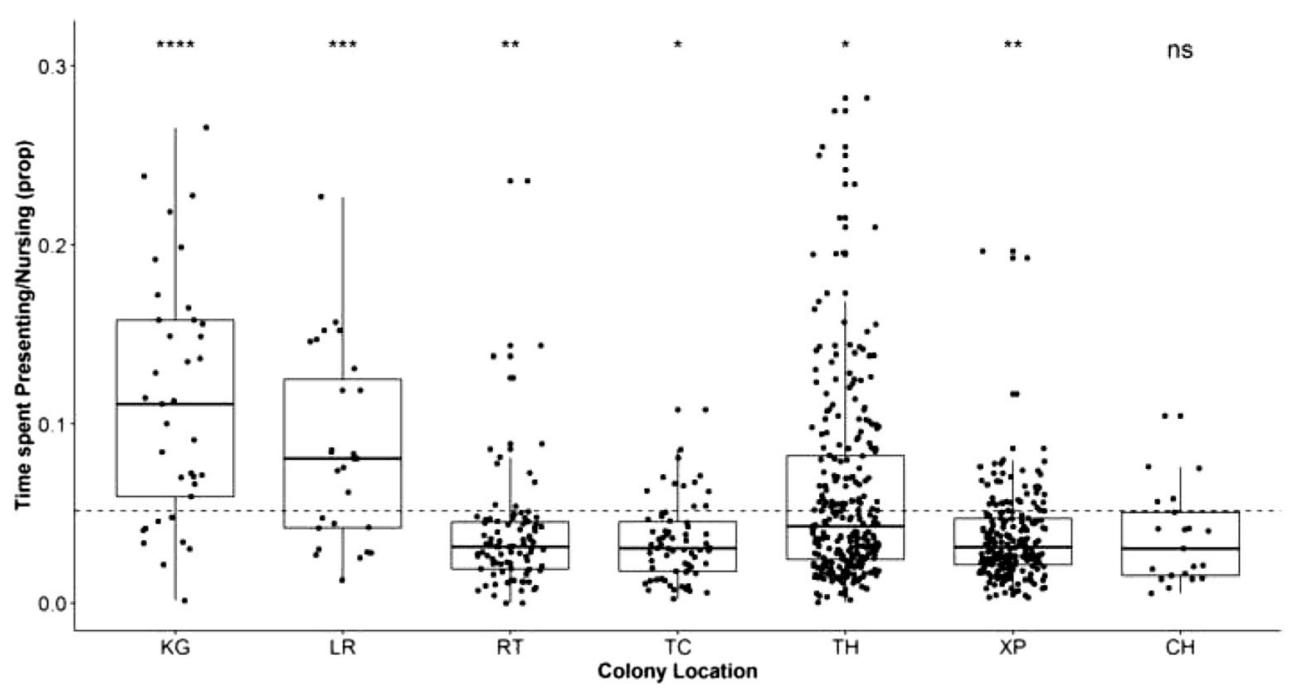

Fig. 5 Boxplot of time spent Presenting/Nursing within each colony location (see Supplemental Fig. 1 for location boundaries and water source locations). The boxes show the median, interquartile range, whiskers (indicating the 90th and 10th percentiles), and individual data points. The dashed horizontal line represents the overall mean time spent Presenting/Nursing. Locations with access to several freshwater sources include Karren's Gully (KG), Loan Road (LR), and Tarbet Hole (TH),

during early development (Mellish et al. 1999) and pups have the highest ratio of milk intake to mass gained during the early days of lactation (Iverson et al. 1993). Stage II of pup development (median days 5-9 of lactation; Woldstad and Jenssen 1999) may therefore be an important developmental milestone whereby pups must lay down their initial fat stores while both mothers and pups remain relatively inactive, maximizing mass-transfer. As pups approach stage IV near the end of lactation, mothers are approaching estrus and likely remain more vigilant due to more frequent interactions with males (Anderson and Fedak 1985; Tinker et al. 1995; Lidgard et al. 2001; Bean et al. 2004; Twiss et al. 2006; Bishop et al. 2017).

Previous work on grey seals in the UK indicate that mothers expend up to $10 \%$ more energy over gestation and lactation for male pups than female pups and spend significantly more time defending and nursing male pups than female pups (Anderson and Fedak 1987; Kovacs 1987). While it was found that grey seal mothers spent significantly more time Alert and significantly less time Resting with female pups than with male pups, it is unclear how much regional differences influence patterns of maternal investment, but the results presented here indicate that populations may experience different pressures on time allocation with regard to pup sex.

Trade-offs between the acquisition of resources and vigilance behaviours have been examined in a variety of predator and prey contexts in terrestrial mammals, with varying degrees of density-dependence identified (Caro 1987; Burger and Gochfeld 1994; Hunter and Skinner 1998; Pangle and while the remaining sites had no or extremely limited access to freshwater pools (Rona Top (RT); Tennis Court (TC); Cross Park (XP); Chapel $(\mathrm{CH})$ ). Grey seal mothers at $\mathrm{KG}$ and LR spent the longest average time Presenting/Nursing, while those in XP and TC had the least. Significance of deviation from the mean (as determined from a Wilxoxon rank sum) indicated by '****' $(p<0.0001)$, '***' $(p<0.001)$, '**' $(p<0.01)$, '*' $(p=0.05)$ or ' $n s$ ' across the top

Holekamp 2010). In herding prey species, higher conspecific density can mean that certain individuals are able to spend less time Alert for predators, devoting a greater proportion of their time activity towards foraging or maternal care (Burger and Gochfeld 1994; Hunter and Skinner 1998). These trade-offs are also applicable where individuals must strike a balance between the energetic cost of foraging as a function of distance and search time and the acquisition of energy upon locating sufficient resources in the environment (Hill et al. 2003; Lagarde et al. 2008; Therrien et al. 2008; Watanabe et al. 2012; Patrick et al. 2014; Battaile et al. 2015; Flack et al. 2016; Costelloe and Rubenstein 2018). These examples principally illustrate the relationships between conserving or acquiring energy and expending energy to ensure survival.

Grey seal mothers have been shown to have poor pupping success following a year with exceptional resource output into a larger pup (Pomeroy et al. 1999). Preliminary analyses indicate that Resting and Alert have very different energetic costs across individuals, as indicated by significantly different mean heart rate (HR) associated with these behaviours. For the same seals studied in this paper, mean HR ( \pm SE) across $n=6,099$ 100-beat traces where the seal was Resting for $>50 \%$ of those beats was $84.4 \pm 0.18 \mathrm{bpm}$. By contrast, mean HR across $n=$ 2,504 100-beat traces where the seal was Alert for $>50 \%$ Alert $92.6 \pm 0.28 \mathrm{bpm}$ (SDT, unpublished data). Mean heart rate has been shown to be a reliable proxy of total energy expenditure across a wide range of taxa and behaviours, where higher mean heart rate indicates more energy spent on an activity (Signer et al. 2011; Turbill et al. 2011; Hawkes et al. 2014; Portugal et al. 2016, 2018). Balancing time spent 
Resting and Alert may be key to lactating grey seals as they attempt to optimize resource availability for their current offspring while minimizing the impact of the associated longerterm costs on the next breeding cycle, though the actual energetic costs of engaging in these two behaviours is currently unknown. These differences in energy costs for Resting and Alert behaviours certainly indicate that there may be tangible energetic consequences that may result from individual differences in time-activity trade-offs, but these costs need to be investigated further. Tracking these behaviours across years may reveal consistent mothering strategies that may relate to different ways of managing these trade-offs with respect to ultimate fitness outcomes.

Measures of heart rate variability, such as rMSSD, have been linked to a continuum of stress-coping styles in laboratory experiments, also known as the pro-reactive spectrum (Koolhaas et al. 1999). Individuals that display low HRV tend to be those classed as proactive and exhibit stereotypical, routine action patterns in a variety of contexts (Coppens et al. 2010). Those individuals that tend towards higher HRV show a more reactive coping style, where the inputs of the surrounding environment tend to elicit responses and dictate the degree of responsiveness to a greater extent than internally regulated control (Coppens et al. 2010). Our study shows that differences in stress-coping styles appear to be important in determining the balance point of trade-offs in whole activity budgets. Grey seal mothers at the proactive end of the spectrum (lower values of rMSSD) spent generally more time Alert and less time Resting than those with a more reactive stress-coping style (Fig. 3a, b). While we did not investigate the frequency of these behaviours in time, proactive individuals may be regularly engaging in Alert vigilance behaviour interspersed with Resting and other behaviours to maintain constant and consistent vigilance effort over time as a mechanism for mitigating overall stress responses, rather than reacting to stressors as they occur (Twiss et al. 2012). These results here may explain in part the observed differences in fitness outcomes for the same population of grey seals (Twiss et al. 2012), but needs to be investigated further.

Few efforts to date have focused on differences between day and night behaviour in grey seals. An early study by Anderson (1978) concluded that behaviour did not differ between day and night other than a higher frequency of 'looks' during day and twilight hours (Anderson 1978). More recently, two studies have found that grey seal mothers Rested significantly more and were Alert significantly less during nighttime hours, though these studies did not monitor behaviour throughout the entire night (Culloch et al. 2016; Fraser et al. 2019). The current study used accelerometers to measure behaviour through the day and night hours, and has confirmed unequivocally that Resting occurs at night along with a marked reduction in vigilance. Alert and other vigilance- type behaviours likely decrease at night due to a decrease in visual acuity, relying more on other sensory inputs to maintain contact with their pup and to intercept incoming threats (Schusterman and Balliet 1971; Schusterman 1974; Culloch et al. 2016). Given the evidence for significant differences between night and day for all behavioural categories examined here, previous studies that (explicitly or implicitly) used time-activity data gathered only during daylight hours as a proxy for behavioural energy usage or behavioural maternal investment (e.g. Kovacs and Lavigne 1986; Twiss et al. 2000) may be misleading. Artificial light pollution has already been shown to significantly alter behaviour for many coastal species and is identified as an ever increasing problem (Davies et al. 2013, 2014; Kamrowski et al. 2013; Yorzinski et al. 2015). If seals are exploiting night as a means of energy conservation and rebalancing time-activity trade-offs because of decreased visual acuity among conspecifics, artificial light pollution may impact this. While the Isle of May is largely undisturbed by human impact, encroaching human settlements towards mainland breeding sites may alter the nighttime activity in grey seals and other landbreeding phocid species, especially for areas of newly formed breeding colonies and more ephemerally populated haul-out sites along the coasts of the UK.

\section{Patterns in Presenting/Nursing}

The results presented here show that Presenting/Nursing behaviour remains constant across lactation, but differs across some colony locations, between day and night, and with respect to rMSSD. These modelled effects, however, were equal in predictive power to our null model and therefore must be regarded as tentative patterns. Intuitively, consistency in Presenting/Nursing effort across lactation should be highly selected for in order to maximize the likelihood that energy can be transferred to the pup. While the number of nursing attempts, or time spent Presenting/Nursing here, is not an accurate measure for amount of energy transferred (Cameron 1998), a theoretical minimum in Presenting/Nursing effort must exist and is likely strongly selected for in these seals. Given that we are also unable to follow the behaviour of the pup through accelerometry, Presenting/Nursing effort remains a loose approximation of maternal investment and can also be heavily influenced by proximity to the pup, the pup's effort to nurse, milk production capacity, and hormone levels (Robinson et al. 2015, 2016). Likewise, seals should not overexert their energy output during lactation, or they risk jeopardizing subsequent breeding attempts (Pomeroy et al. 1999; McMahon et al. 2016; Bubac et al. 2018). Pup survival is highly dependent on the mass at which it is weaned (Hall et al. 2001), a 
common feature across a wide range of taxa (Pilastro et al. 1994; Festa-Bianchet et al. 2000; Hall et al. 2001; Harding et al. 2005; Ozgul et al. 2010; Bowen et al. 2015; Weitzman et al. 2017). As a result, mothers are likely less able to be flexible in trading-off time spent Presenting/ Nursing with other behaviours over lactation in order to maximize energy transfer to her pup.

Bowen et al. (1992) found no pup sex dependent differences in grey seal mother energy expenditures on Sable Island (Canada), while studies in the UK indicated differences in investment between pup sexes (Anderson and Fedak 1987). Here, we found no detectable difference in time spent Presenting/Nursing across pup sexes. These conflicting results may indicate that some regional or colony-specific differences may be at play. Resting HRV had some support in models of time spent Presenting/ Nursing, but did not show any clear patterns (Fig. 3c). This lack of distinct pattern further supports our conclusion that consistency in Presenting/Nursing effort is highly selected for, irrespective of individual coping style. By using accelerometers, we also found that grey seal mothers are often engaging in Presenting/Nursing effort significantly more overnight. Presenting/Nursing more overnight likely help to stabilize maternal effort over time, especially when social and aggressive interactions may limit the amount of time during the day that mothers can nurse.

The greatest source of apparent variability in time spent Presenting/Nursing was found in the different subregions of the island. The study colony (Isle of May) is topographically heterogeneous (see Supplemental Fig. 1; Twiss et al. 2000). In particular, access to water varies considerably, and previous work has demonstrated that lactating females prefer access to fresh water (Twiss et al. 2000, 2002; Redman et al. 2001; Stewart et al. 2014). The thick blubber layer of all phocids provides insulation and grey seals will often use freshwater pools to achieve the benefits of evaporative cooling (Rommel et al. 1995; Boily and Lavigne 1996; Twiss et al. 2002; Khamas et al. 2012; Paterson et al. 2012). With the increased metabolic demands of lactating while fasting, grey seal mothers may also prefer access to freshwater as a means to drink to meet water demands (Stewart et al. 2014). Areas with the poorest access to temporary freshwater pools (Cross Park - XP, Tennis Court - TC, and Rona Top - RT; Fig. 5) tended to have mothers that spent significantly less time Presenting/Nursing on average than those containing permanent and stable freshwater sources. Therefore, time spent travelling to and from pools to drink or cool off may potentially impact time spent Presenting/Nursing day to day. Alternatively, some grey seal mothers may simply go without drinking, minimizing geographic movement and energy used for activity as a means of compensating for increased expense of burning more internal resources to free up body water (Reilly and Fedak 1990). It remains to be seen whether either strategy may impact energy leftover for lactation and how this may affect pup development. Locomotory behaviours were poorly identified in the current study design (see Shuert et al. 2018) which prevents an accurate assessment of movement across the colony to and from freshwater sources, without the aid of additional sensors like GPS or magnetometers for dead-reckoning.

No support was identified for extrinsic environmental variables influencing behaviour in the current investigation. Weather variables were measured as summaries over an hour at a single location on the island, therefore it is likely that the spatial and temporal resolution of the environmental data was too coarse to link to individual behavioural decisions with respect to thermoregulatory or water balance needs. Spatial differences in local weather variables across the island may have also contributed to differences in Presenting/Nursing behaviour, but it was not possible to assess environmental variables at such a fine spatial resolution in the current study. A fine-scale analysis of environmental conditions associated with time and energy management in grey seals may reveal more about behavioural responses to extrinsic drivers, especially given the projected changes in climate variability for the autumnal breeding season in the UK (Jenkins et al. 2008).

\section{Conclusions}

Using the high-resolution data from accelerometers, we were able to identify behavioural trade-offs between rest (Resting) and vigilance (Alert) in a capital breeding pinniped. Stress-coping styles, measured through the metric rMSSD, have an important influence on how individuals resolve this trade-off throughout the duration of lactation. Time devoted to Presenting/Nursing as a behavioural state is more fixed within an individual, but potentially varies across individuals depending upon local topography. Therefore, only certain aspects of time-activity budgets are labile and available for modification of allocated time as individuals attempt to balance current breeding activity while maintaining enough resources to successfully complete lactation the next season. Incorporating the dynamics of these trade-offs on whole activity budgets as well as the modulating effect of stress-coping styles on behaviour will enhance our understanding of how individuals optimize energy usage trajectories over time.

Acknowledgments The authors wish to acknowledge S. Moss for implementation and field operations associated with this study. We would also like to acknowledge additional field support from the rest of the Isle of 
May field crew in 2015 and 2016. The authors also wish to thank two anonymous reviewers for comments to improve an earlier version of this manuscript.

Funding information Funding for this work was provided the Durham Doctoral Studentship scheme (awarded to the lead author, CRS) at Durham University, as well as National Environmental Research Council's long term funding to the Sea Mammal Research Unit at the University of St. Andrews (PPP, project title: "SMRU Long-term measurement of marine mammal population structure, dynamics and trophic interactions", grant reference SMRU1001).

Data availability The datasets generated and analysed during the current study are available from the corresponding author on reasonable request.

\section{Compliance with ethical standards}

Conflict of interest The authors declare that they have no conflict of interest.

Ethical approval All applicable international, national, and/or institutional guidelines for the care and use of animals were adhered to in this study. All animal procedures were performed under UK Home Office project licence \#60/4009 and conformed to the UK Animals (Scientific Procedures) Act, 1986. All research was approved ethically by the Durham University Animal Welfare Ethical Review Board as well as by the University of St. Andrews Animal Welfare and Ethics Committee.

Open Access This article is licensed under a Creative Commons Attribution 4.0 International License, which permits use, sharing, adaptation, distribution and reproduction in any medium or format, as long as you give appropriate credit to the original author(s) and the source, provide a link to the Creative Commons licence, and indicate if changes were made. The images or other third party material in this article are included in the article's Creative Commons licence, unless indicated otherwise in a credit line to the material. If material is not included in the article's Creative Commons licence and your intended use is not permitted by statutory regulation or exceeds the permitted use, you will need to obtain permission directly from the copyright holder. To view a copy of this licence, visit http://creativecommons.org/licenses/by/4.0/.

\section{References}

Altmann J (1974) Observational study of behavior: sampling methods. Behaviour 49:227-267. https://doi.org/10.1163/156853974X00534

Anderson SS (1978) Day and night activity of Grey seal bulls. Mammal Rev 8:43-46. https://doi.org/10.1111/j.1365-2907.1978.tb00215.x

Anderson DR (2008) Model based inference in the life sciences: a primer on evidence. Springer Science \& Business Media, Berlin

Anderson SS, Fedak MA (1985) Grey seal males: energetic and behavioural links between size and sexual success. Anim Behav 33:829 838. https://doi.org/10.1016/S0003-3472(85)80017-8

Anderson SS, Fedak MA (1987) Grey seal, Halichoerus grypus, energetics: females invest more in male offspring. J Zool 211:667-679. https://doi.org/10.1111/j.1469-7998.1987.tb04478.x

Anderson DR, Burnham KP, White GC (1998) Comparison of Akaike information criterion and consistent Akaike information criterion for model selection and statistical inference from capture-recapture studies. J Appl Stat 25:263-283. https://doi.org/10.1080/02664769823250

Andrews RD, Enstipp MR (2016) Diving physiology of seabirds and marine mammals: relevance, challenges and some solutions for field studies. Comp Biochem Physiol A 202:38-52. https://doi.org/10. 1016/j.cbpa.2016.07.004

Arenz CL, Leger DW (1999) Thirteen-lined ground squirrel (Sciuridae: Spermophilus tridecemlineatus) antipredator vigilance decreases as vigilance cost increases. Anim Behav 57:97-103. https://doi.org/10. 1006/anbe.1998.0963

Barton K (2018) MuMIn: Multi-Model Inference. R Package version 1(43):6 https://CRAN.R-project.org/package=MuMIn

Battaile BC, Sakamoto KQ, Nordstrom CA, Rosen DAS, Trites AW (2015) Accelerometers identify new behaviors and show little difference in the activity budgets of lactating northern fur seals (Callorhinus ursinus) between breeding islands and foraging habitats in the eastern Bering Sea. PLoS One 10:e0118761. https://doi. org/10.1371/journal.pone.0118761

Bean K, Amos W, Pomeroy PP, Twiss SD, Coulson TN, Boyd IL (2004) Patterns of parental relatedness and pup survival in the grey seal (Halichoerus grypus). Mol Ecol 13:2365-2370. https://doi.org/10. 1111/j.1365-294X.2004.02199.x

Beauchamp G (2007) Exploring the role of vision in social foraging: what happens to group size, vigilance, spacing, aggression and habitat use in birds and mammals that forage at night? Biol Rev 82:511-525. https://doi.org/10.1111/j.1469-185X.2007.00021.x

Bennett KA, Speakman JR, Moss SEW, Pomeroy P, Fedak MA (2007) Effects of mass and body composition on fasting fuel utilisation in grey seal pups (Halichoerus grypus Fabricius): an experimental study using supplementary feeding. J Exp Biol 210:3043-3053. https://doi.org/10.1242/jeb.009381

Bishop AM, Stewart JE, Pomeroy P, Twiss SD (2017) Intraseasonal temporal variation of reproductive effort for male grey seals. Anim Behav 134:167-175. https://doi.org/10.1016/j.anbehav.2017.10.021

Biuw M, McConnell B, Bradshaw CJA, Burton H, Fedak M (2003) Blubber and buoyancy: monitoring the body condition of freeranging seals using simple dive characteristics. J Exp Biol 206: 3405-3423. https://doi.org/10.1242/jeb.00583

Boily P, Lavigne DM (1996) Thermoregulation of juvenile grey seals, Halichoerus grypus, in air. Can J Zool 74:201-208. https://doi.org/ 10.1139/z96-025

Bolker B, RCD Team (2017) bbmle: Tools for General Maximum Likelihood Estimation. R package version 1.0.20. https://CRAN. R-project.org/package=bbmle

Bolker BM, Brooks ME, Clark CJ, Geange SW, Poulsen JR, Stevens MHH, White JSS (2009) Generalized linear mixed models: a practical guide for ecology and evolution. Trends Ecol Evol 24:127-135. https://doi.org/10.1016/j.tree.2008.10.008

Bowen WD, Stobo WT, Smith SJ (1992) Mass changes of grey seal Halichoerus grypus pups on Sable Island: differential maternal investment reconsidered. J Zool 227:607-622. https://doi.org/10. 1111/j.1469-7998.1992.tb04418.x

Bowen WD, den Heyer CE, McMillan JI, Iverson SJ (2015) Offspring size at weaning affects survival to recruitment and reproductive performance of primiparous gray seals. Ecol Evol 7:1412-1424. https://doi.org/10.1002/ece3.1450

Briefer EF, Oxley JA, McElligott AG (2015) Autonomic nervous system reactivity in a free-ranging mammal: effects of dominance rank and personality. Anim Behav 110:121-132. https://doi.org/10.1016/j. anbehav.2015.09.022

Bubac CM, Coltman DW, Don Bowen W, Lidgard DC, Lang SLC, den Heyer CE (2018) Repeatability and reproductive consequences of boldness in female gray seals. Behav Ecol Sociobiol 72:100-112. https://doi.org/10.1007/s00265-018-2515-5

Burger J, Gochfeld M (1994) Vigilance in african mammals: differences among mothers, other females, and males. Behaviour 131:153-169. https://doi.org/10.1163/156853994X00415

Burnham KP, Anderson DR (2002) Model selection and multimodel inference: a practical information-theoretic approach, 2nd edn. Springer-Verlag, Berlin 
Burnham KP, Anderson DR, Huyvaert KP (2011) AIC model selection and multimodel inference in behavioral ecology: some background, observations, and comparisons. Behav Ecol Sociobiol 65:23-35. https://doi.org/10.1007/s00265-010-1029-6

Byrnes G, Lim NT-L, Yeong C, Spence AJ (2011) Sex differences in the locomotor ecology of a gliding mammal, the Malayan colugo (Galeopterus variegatus). J Mammal 92:444-451. https://doi.org/ 10.1644/10-MAMM-A-048.1

Cameron EZ (1998) Is suckling behaviour a useful predictor of milk intake? A review. Anim Behav 56:521-532. https://doi.org/10. 1006/anbe.1998.0793

Caro TM (1987) Cheetah mothers' vigilance: looking out for prey or for predators? Behav Ecol Sociobiol 20:351-361. https://doi.org/10. 1007/BF00300681

Coppens CM, de Boer SF, Koolhaas JM (2010) Coping styles and behavioural flexibility: towards underlying mechanisms. Phil Trans R Soc B 365:4021-4028. https://doi.org/10.1098/rstb.2010.0217

Costelloe BR, Rubenstein DI (2018) Temporal structuring of vigilance behaviour by female Thomson's gazelles with hidden fawns. Anim Behav 145:87-97. https://doi.org/10.1016/j.anbehav.2018.09.007

Culloch RM, Pomeroy PP, Twiss SD (2016) The difference between night and day: the nocturnal and diurnal activity budget of gray seals (Halichoerus grypus) during the breeding season. Mar Mammal Sci 32:400-408. https://doi.org/10.1111/mms.12259

Davies TW, Bennie J, Inger R, de Ibarra NH, Gaston KJ (2013) Artificial light pollution: are shifting spectral signatures changing the balance of species interactions? Glob Chang Biol 19:1417-1423. https://doi. org/10.1111/gcb.12166

Davies TW, Duffy JP, Bennie J, Gaston KJ (2014) The nature, extent, and ecological implications of marine light pollution. Front Ecol Environ 12:347-355. https://doi.org/10.1890/130281

Desprez M, Gimenez O, McMahon CR, Hindell MA, Harcourt RG (2018) Optimizing lifetime reproductive output: intermittent breeding as a tactic for females in a long-lived, multiparous mammal. J Anim Ecol 87:199-211. https://doi.org/10.1111/1365-2656.12775

Fedak MA, Anderson SS (1982) The energetics of lactation: accurate measurements from a large wild mammal, the Grey seal (Halichoerus grypus). J Zool 198:473-479. https://doi.org/10. 1111/jzo.1982.198.4.473

Festa-Bianchet M, Gaillard J, Jorgenson JT (1998) Mass- and densitydependent deproductive success and reproductive costs in a capital breeder. Am Nat 152:367-379. https://doi.org/10.1086/286175

Festa-Bianchet M, Jorgenson JT, Reale D (2000) Early development, adult mass, and reproductive success in bighorn sheep. Behav Ecol 11:633-639. https://doi.org/10.1093/beheco/11.6.633

Flack A, Fiedler W, Blas J, Pokrovsky I, Kaatz M, Mitropolsky M, Aghababyan K, Fakriadis I, Makrigianni E, Jerzak L, Azafzaf H, Feltrup-Azafzaf C, Rotics S, Mokotjomela TM, Nathan R, Wikelski M (2016) Costs of migratory decisions: a comparison across eight white stork populations. Sci Adv 2:e1500931. https://doi.org/10. 1126/sciadv.1500931

Fraser ZL, Culloch RM, Twiss SD (2019) As clear as day: nocturnal activity differs from diurnal activity in a temporarily constrained capital breeder. Behaviour 156:997-1016. https://doi.org/10.1163/ 1568539X-00003553

Goldbogen JA, Calambokidis J, Shadwick RE, Oleson EM, McDonald MA, Hildebrand JA (2006) Kinematics of foraging dives and lungefeeding in fin whales. J Exp Biol 209:1231-1244. https://doi.org/10. 1242/jeb. 02135

Goldbogen JA, Calambokidis J, Friedlaender AS, Francis J, DeRuiter SL, Stimpert AK, Falcone E, Southall BL (2013) Underwater acrobatics by the world's largest predator: $360^{\circ}$ rolling manoeuvres by lungefeeding blue whales. Biol Lett 9:20120986. https://doi.org/10.1098/ rsbl.2012.0986

Grandi LC, Ishida H (2015) The physiological effect of human grooming on the heart rate and the heart rate variability of laboratory non- human primates: a pilot study in male rhesus monkeys. Front Vet Sci 2:1-9. https://doi.org/10.3389/fvets.2015.00050

Hall AJ, McConnell BJ, Barker RJ (2001) Factors affecting first-year survival in grey seals and their implications for life history strategy. J Anim Ecol 70:138-149. https://doi.org/10.1046/j.1365-2656. 2001.00468.x

Harding KC, Fujiwara M, Axberg Y, Härkönen T (2005) Mass-dependent energetics and survival in harbour seal pups. Funct Ecol 19:129 135. https://doi.org/10.1111/j.0269-8463.2005.00945.x

Harris RE, Miller GW, Richardson WJ (2001) Seal responses to airgun sounds during summer seismic surveys in the Alaskan Beaufort Sea. Mar Mammal Sci 17:795-812. https://doi.org/10.1111/j.1748-7692. 2001.tb01299.x

Hastings KK, Gelatt TS, King JC (2009) Postbranding survival of Steller sea lion pups at Lowrie Island in southeast Alaska. J Wildlife Manage 73:1040-1051. https://doi.org/10.2193/2007-208

Hastings KK, Jemison LA, Gelatt TS, Laake JL, Pendleton GW, King JC, Trites AW, Pitcher KW (2011) Cohort effects and spatial variation in age-specific survival of Steller sea lions from southeastern Alaska. Ecosphere 2:art111. https://doi.org/10.1890/ES11-00215.1

Hawkes LA, Butler PJ, Frappell PB, Meir JU, Milsom WK, Scott GR, Bishop CM (2014) Maximum running speed of captive bar-headed geese is unaffected by severe hypoxia. PLoS One 9:e94015. https:// doi.org/10.1371/journal.pone.0094015

Heerah K, Andrews-Goff V, Williams G, Sultan E, Hindell M, Patterson T, Charrassin JB (2013) Ecology of Weddell seals during winter: influence of environmental parameters on their foraging behaviour. Deep-Sea Res P II 88-89:23-33. https://doi.org/10.1016/j.dsr2. 2012.08.025

Hill RA, Barrett L, Gaynor D, Weingrill A, Dixson P, Payne H, Henzi SP (2003) Day length, latitude and behavioural (in)flexibility in baboons (Papio cynocephalus ursinus). Behav Ecol Sociobiol 53: 278-286. https://doi.org/10.1007/s00265-003-0590-7

Horning M, Mellish J-AE (2012) Predation on an upper trophic marine predator, the Steller sea lion: evaluating high juvenile mortality in a density dependent conceptual framework. PLoS One 7:e30173. https://doi.org/10.1371/journal.pone.0030173

Hunter LTB, Skinner JD (1998) Vigilance behavior in African ungulates: the role of predation pressure. Behaviour 135:195-211 https://www. jstor.org/stable/4535519

Iverson SJ, Bowen WD, Boness DJ, Oftedal OT (1993) The effect of maternal size and milk energy output on pup growth in grey seals (Halichoerus grypus). Physiol Zool 66:61-88. https://doi.org/10. 1086/physzool.66.1.30158287

Jeanniard-du-dot T, Guinet C, Arnould JPY, Speakman JR, Trites AW (2017) Accelerometers can measure total and activity-specific energy expenditures in free-ranging marine mammals only if linked to time-activity budgets. Funct Ecol 31:377-386. https://doi.org/10. 1111/1365-2435.12729

Jenkins GJ, Perry MC, Prior MJ (2008) The climate of the United Kingdom and recent trends. Met Office Hadley Centre, Exeter, UK

Kamrowski RL, Limpus C, Moloney J, Hamann M (2013) Coastal light pollution and marine turtles: assessing the magnitude of the problem. Endanger Species Res 19:85-98. https://doi.org/10.3354/esr00462

Khamas WA, Smodlaka H, Leach-Robinson J, Palmer L (2012) Skin histology and its role in heat dissipation in three pinniped species. Acta Vet Scand 54:46. https://doi.org/10.1186/1751-0147-54-46

Koolhaas JM, Korte SM, de Boer SF, Van Der Vegt BJ, Van Reenen CG, Hopster H, De Jong IC, Ruis MAW, Blokhuis HJ (1999) Coping styles in animals: current in behavior and stress-physiology. Neurosci Biobehav Rev 23:925-935. https://doi.org/10.1016/ S0149-7634(99)00026-3

Koolhaas JM, de Boer SF, Coppens CM, Buwalda B (2010) Neuroendocrinology of coping styles: towards understanding the biology of individual variation. Front Neuroendocrinol 31:307321. https://doi.org/10.1016/j.yfrne.2010.04.001 
Koolhaas JM, Bartolomucci A, Buwalda B, de Boer SF, Flügge G, Korte SM, Meerlo P, Murison R, Olivier B, Palanza P, Richter-Levin G, Sgoifo A, Steimer T, Stiedl O, van Dijk G, Wöhr M, Fuchs E (2011) Stress revisited: a critical evaluation of the stress concept. Neurosci Biobehav Rev 35:1291-1301. https://doi.org/10.1016/j.neubiorev.2011.02.003

Kovacs KM (1987) Maternal behaviour and early behavioural ontogeny of grey seals (Halichoerus grypus) on the Isle of May, UK. J Zool 213:697-715. https://doi.org/10.1111/j.1469-7998.1987.tb03735.x

Kovacs KM, Lavigne DM (1986) Maternal investiment and neonatal growth in phocid seals. J Anim Ecol 55:1035-1051. https://doi. org $/ 10.2307 / 4432$

Lagarde F, Guillon M, Dubroca L, Bonnet X, Ben Kaddour K, Slimani T, El Mouden EH (2008) Slowness and acceleration: a new method to quantify the activity budget of chelonians. Anim Behav 75:319 329. https://doi.org/10.1016/j.anbehav.2007.01.010

Lidgard DC, Boness DJ, Bowen WD (2001) A novel mobile approach to investigating mating tactics in male grey seals (Halichoerus grypus). J Zool 255:313-320. https://doi.org/10.1017/S0952836901001418

Liu J, Wei W, Kuang H, Tsien JZ, Zhao F (2014) Heart rate and heart rate variability assessment identifies individual differences in fear response magnitudes to earthquake, free fall, and air puff in mice. PLoS One 9:e93270. https://doi.org/10.1371/journal.pone.0093270

Liwanag HEM, Williams TM, Costa DP, Kanatous SB, Davis RW, Boyd IL (2009) The effects of water temperature on the energetic costs of juvenile and adult California sea lions (Zalophus californianus): the importance of skeletal muscle thermogenesis for thermal balance. $\mathrm{J}$ Exp Biol 212:3977-3984. https://doi.org/10.1242/jeb.033282

Loison A, Langvatn R, Solberg EJ (1999) Body mass and winter mortality in red deer calves: disentangling sex and climate effects. Ecography 22:20-30. https://doi.org/10.1111/j.1600-0587.1999. tb00451.x

Lydersen C, Kovacs KM (1999) Behaviour and energetics of ice-breeding, North Atlantic phocid seals during the lactation period. Mar Ecol Prog Ser 187:265-281. https://doi.org/10.3354/meps187265

Magnusson A, Skaug HJ, Nielsen A, Berg CW, Kristensen K, Maechler M, van Bentham KJ, Bolker BM, Brooks ME (2017) glmmTMB: generalized linear mixed models using template model builder. https://journal.r-project.org/archive/2017/RJ-2017-006/index.html

Maniscalco JM (2014) The effects of birth weight and maternal care on survival of juvenile Steller Sea lions (Eumetopias jubatus). PLoS One 9:e96328. https://doi.org/10.1371/journal.pone.0096328

Maniscalco JM, Springer AM, Parker P (2010) High natality rates of endangered Steller Sea lions in Kenai Fjords, Alaska and perceptions of population status in the Gulf of Alaska. PLoS One 5: e10076. https://doi.org/10.1371/journal.pone.0010076

Marchant-Forde RM, Marlin DJ, Marchant-Forde JN (2004) Validation of a cardiac monitor for measuring heart rate variability in adult female pigs: accuracy, artefacts and editing. Physiol Behav 80: 449-458. https://doi.org/10.1016/j.physbeh.2003.09.007

McDonald BI, Crocker DE (2006) Physiology and behavior influence lactation efficiency in Northern elephant seals (Mirounga angustirostris). Physiol Biochem Zool Ecol Evol Approaches 79: 484-496. https://doi.org/10.1086/501056

McMahon CR, Burton HR, Bester MN (2000) Weaning mass and the future survival of juvenile southern elephant seals, Mirounga leonina, at Macquarie Island. Antarct Sci 12:149-153. https://doi. org/10.1017/S0954102000000195

McMahon CR, Harcourt RG, Burton HR, Daniel O, Hindell MA (2016) Seal mothers expend more on offspring under favourable conditions and less when resources are limited. J Anim Ecol 86:359-370. https://doi.org/10.1111/1365-2656.12611

Mellish J-AE, Iverson SJ, Bowen WD (1999) Variation in milk production and lactation performance in grey seals and consequences for pup growth and weaning characteristics. Physiol Biochem Zool 72: 677-690. https://doi.org/10.1086/316708
Mellish J-AE, Iverson SJ, Bowen WD (2000) Metabolic compensation during high energy output in fasting, lactating grey seals (Halichoerus grypus): metabolic ceilings revisited. Proc R Soc B 267:1245-1251. https://doi.org/10.1098/rspb.2000.1134

Monestier C, Morelle N, Gaillard JM, Cargnelutti B, Vanpé C, Hewison AJM (2015) Is a proactive mum a good mum? A mother's coping style influences early fawn survival in roe deer. Behav Ecol 26: 1395-1403. https://doi.org/10.1093/beheco/arv087

Murie DJ, Lavigne DM (1991) Food consumption of wintering harp seals, Phoca groenlandica, in the St. Lawrence estuary, Canada. Can J Zool 69:1289-1296. https://doi.org/10.1139/z91-181

Naito Y, Bornemann H, Takahashi A, McIntyre T, Plötz J (2010) Finescale feeding behavior of Weddell seals revealed by a mandible accelerometer. Polar Sci 4:309-316. https://doi.org/10.1016/j.polar. 2010.05.009

Noren DP (2002) Thermoregulation of weaned northern elephant seal (Mirounga angustirostris) pups in air and water. Physiol Biochem Zool 75:513-523. https://doi.org/10.1086/342254

Ozgul A, Childs DZ, Oli MK, Armitage KB, Blumstein DT, Olson LE, Tuljapurkar S, Coulson T (2010) Coupled dynamics of body mass and population growth in response to environmental change. Nature 466:482-485. https://doi.org/10.1038/nature09210

Pagano AM, Durner GM, Rode KD, Atwood TC, Atkinson SN, Peacock E, Costa DP, Owen MA, Williams TM (2018) High-energy, high-fat lifestyle challenges an Arctic apex predator, the polar bear. Science 359:568-572. https://doi.org/10.1126/science.aan8677

Pangle WM, Holekamp KE (2010) Functions of vigilance behaviour in a social carnivore, the spotted hyaena, Crocuta crocuta. Anim Behav 80:257-267. https://doi.org/10.1016/j.anbehav.2010.04.026

Paterson W, Sparling CE, Thompson D, Pomeroy PP, Currie J, McCafferty DJ (2012) Seals like it hot: changes in surface temperature of harbour seals (Phoca vitulina) from late pregnancy to moult. J Therm Biol 37: 454-461. https://doi.org/10.1016/j.jtherbio.2012.03.004

Patrick SC, Bearhop S, Grémillet D, Lescroël A, Grecian WJ, Bodey TW, Hamer KC, Wakefield E, Le Nuz M, Votier SC (2014) Individual differences in searching behaviour and spatial foraging consistency in a central place marine predator. Oikos 123:33-40. https://doi.org/ 10.1111/j.1600-0706.2013.00406.x

Pilastro A, Gomiero T, Marin G (1994) Factors affecting body mass of young fat dormice (Glis glis) at weaning and by hibernation. J Zool 234:13-23. https://doi.org/10.1111/j.1469-7998.1994.tb06053.x

Pohlin F, Brabender K, Fluch G, Stalder G, Petit T, Walzer C (2017) Seasonal variations in heart rate variability as an indicator of stress in free-ranging pregnant Przewalski's horses (E. ferus przewalskii) within the Hortobágy National Park in Hungary. Front Physiol 8:111. https://doi.org/10.3389/fphys.2017.00664

Pomeroy PP, Fedak MA, Rothery P, Anderson S (1999) Consequences of maternal size for reproductive expenditure and pupping success of grey seals at north Rona, Scotland. J Anim Ecol 68:235-253. https:// doi.org/10.1046/j.1365-2656.1999.00281.x

Pomeroy PP, Twiss SD, Duck CD (2000a) Expansion of a grey seal (Halichoerus grypus) breeding colony: changes in pupping site use at the isle of may, Scotland. J Zool 250:1-12. https://doi.org/ 10.1111/j.1469-7998.2000.tb00573.x

Pomeroy PP, Twiss SD, Redman P (2000b) Philopatry, site fidelity and local kin associations within grey seal breeding colonies. Ethology 106:899-919. https://doi.org/10.1046/j.1439-0310.2000.00610.x

Portugal SJ, Green JA, Halsey LG, Arnold W, Careau V, Dann P, Frappell PB, Grémillet D, Handrich Y, Martin GR, Ruf T, Guillemette MM, Butler PJ (2016) Associations between resting, activity, and daily metabolic rate in free-living endotherms: no universal rule in birds and mammals. Physiol Biochem Zool 89:251-261. https://doi.org/10.1086/686322

Portugal SJ, White CR, Green JA, Butler PJ (2018) Flight feather moult drives minimum daily heart rate in wild geese. Biol Lett 14:6-9. https://doi.org/10.1098/rsbl.2018.0650 
Redman P, Pomeroy PP, Twiss SD (2001) Grey seal maternal attendance patterns are affected by water availability on North Rona, Scotland. Can J Zool 79:1073-1079. https://doi.org/10.1139/cjz-79-6-1073

Reefmann N, Wechsler B, Gygax L (2009) Behavioural and physiological assessment of positive and negative emotion in sheep. Anim Behav 78:651-659. https://doi.org/10.1016/j.anbehav.2009.06.015

Reilly JJ, Fedak MA (1990) Measurement of the body composition of living gray seals by hydrogen isotope dilution. J Appl Physiol 69: 885-891. https://doi.org/10.1152/jappl.1990.69.3.885

Robinson KJ, Twiss SD, Hazon N, Pomeroy PP (2015) Maternal oxytocin is linked to close mother-infant proximity in grey seals (Halichoerus grypus). PLoS One 10:e144577. https://doi.org/10. 1371/journal.pone.0144577

Robinson KJ, Pomeroy PP, Hazon N, Moss S, Twiss SD (2016) Individual size, sex, and rearing environment impact on aggression in newly weaned seals. Mar Mammal Sci:1-9. https://doi.org/10.1111/MMS.12367

Rodriguez-Linares L, Vila X, Lado MJ, Mendez A, Otero A, Garcia CA (2017) RHRV: heart rate variability analysis of ECG data. R package version 4(2):5 https://CRAN.R-project.org/package=RHRV

Rommel SA, Early GA, Matassa KA, Pabst DA, McLellan WA (1995) Venous structures associated with thermoregulation of phocid seal reproductive organs. Anat Rec 243:390-402. https://doi.org/10. 1002/ar.1092430314

Sakamoto KQ, Sato K, Ishizuka M, Watanuki Y, Takahashi A, Daunt F, Wanless S (2009) Can ethograms be automatically generated using body acceleration data from free-ranging birds? PLoS One 4:e5379. https://doi.org/10.1371/journal.pone.0005379

Sami S, Mikko S, Antti K (2004) Artefact correction for heart beat interval data. In: Advanced methods for processing bioelectrical signals. Conference Proceedings, Jyväskylä, pp 1-10

Schmidt A, Möstl E, Wehnert C, Aurich J, Müller J, Aurich C (2010) Cortisol release and heart rate variability in horses during road transport. Horm Behav 57:209-215. https://doi.org/10.1016/j.yhbeh. 2009.11.003

Schusterman RJ (1974) Auditory sensitivity of a California sea lion to airborne sound. J Acoust Soc Am 56:1248-1251. https://doi.org/10. $1121 / 1.1903415$

Schusterman RJ, Balliet RF (1971) Aerial and underwater visual acuity in the California Sea lion (Zalophus californianus) as a function of luminance. Ann N Y Acad Sci 188:37-46. https://doi.org/10.1111/ j.1749-6632.1971.tb13088.x

Shaffer SA, Clatterbuck CA, Kelsey EC, Naiman AD, Young LC, VanderWerf E, Warzybok P, Bradley R, Jahncke J, Bower GC (2014) As the egg turns: monitoring egg attendance behavior in wild birds using novel data logging technology. PLoS One 9:e97898. https://doi.org/10.1371/journal.pone.0097898

Shuert CR, Pomeroy PP, Twiss SD (2018) Assessing the utility and limitations of accelerometers and machine learning approaches in classifying behaviour during lactation in a phocid seal. Anim Biotelemetry 6:14-17. https://doi.org/10.1186/s40317-018-0158-y

Signer C, Ruf T, Arnold W (2011) Hypometabolism and basking: the strategies of Alpine ibex to endure harsh over-wintering conditions. Funct Ecol 25:537-547. https://doi.org/10.1111/j.1365-2435.2010.01806.x

Skinner JP, Norberg SE, Andrews RD (2010) Head striking during fish capture attempts by Steller sea lions and the potential for using head surge acceleration to predict feeding behavior. Endanger Species Res 10:61-69. https://doi.org/10.3354/esr00236

Stewart JE, Pomeroy PP, Duck CD, Twiss SD (2014) Finescale ecological niche modeling provides evidence that lactating gray seals (Halichoerus grypus) prefer access to fresh water in order to drink. Mar Mammal Sci 30:1456-1472. https://doi.org/10.1111/mms.12126

Stothart MR, Elliott KH, Wood T, Hatch SA, Speakman JR (2016) Counting calories in cormorants: dynamic body acceleration predicts daily energy expenditure measured in pelagic cormorants. J Exp Biol 219:2192-2200. https://doi.org/10.1242/jeb.130526
Therrien JF, Côté SD, Festa-Bianchet M, Ouellet JP (2008) Maternal care in white-tailed deer: trade-off between maintenance and reproduction under food restriction. Anim Behav 75:235-243. https://doi. org/10.1016/j.anbehav.2007.04.030

Tinker MT, Kovacs KM, Hammill MO (1995) The reproductive behavior and energetics of male gray seals (Halichoerus grypus) breeding on a land-fast ice substrate. Behav Ecol Sociobiol 36:159-170. https:// doi.org/10.1007/s002650050136

Turbill C, Ruf T, Mang T, Arnold W (2011) Regulation of heart rate and rumen temperature in red deer: effects of season and food intake. $\mathrm{J}$ Exp Biol 214:963-970. https://doi.org/10.1242/jeb.052282

Twiss SD, Caudron A, Pomeroy PP, Thomas CJ, Mills JP (2000) Finescale topographical correlates of behavioural investment in offspring by female grey seals, Halichoerus grypus. Anim Behav 59: 327-338. https://doi.org/10.1006/anbe.1999.1320

Twiss SD, Wright NC, Dunstone N, Redman P, Moss S, Pomeroy PP (2002) Behavioral evidence of thermal stress from overheating in UK breeding gray seals. Mar Mammal Sci 18:455-468. https://doi. org/10.1111/j.1748-7692.2002.tb01048.x

Twiss SD, Duck CD, Pomeroy PP (2003) Grey seal (Halichoerus grypus) pup mortality not explained by local breeding density on North Rona, Scotland. J Zool 259:83-91. https://doi.org/10.1017/ S0952836902003035

Twiss SD, Poland VF, Graves JA, Pomeroy PP (2006) Finding fathers: spatio-temporal analysis of paternity assignment in grey seals (Halichoerus grypus). Mol Ecol 15:1939-1953. https://doi.org/10. 1111/j.1365-294X.2006.02927.x

Twiss SD, Cairns C, Culloch RM, Richards SA, Pomeroy PP (2012) Variation in female grey seal (Halichoerus grypus) reproductive performance correlates to proactive-reactive behavioural types. PLoS One 7:e49598. https://doi.org/10.1371/journal.pone.0049598

Udyawer V, Simpfendorfer CA, Heupel MR, Clark TD (2017) Temporal and spatial activity-associated energy partitioning in free-swimming sea snakes. Funct Ecol 31:1739-1749. https://doi.org/10.1111/13652435.12882

Viviant M, Trites AW, Rosen DAS, Monestiez P, Guinet C (2010) Prey capture attempts can be detected in Steller sea lions and other marine predators using accelerometers. Polar Biol 33:713-719. https://doi. org/10.1007/s00300-009-0750-y

von Borell E, Langbein J, Després G et al (2007) Heart rate variability as a measure of autonomic regulation of cardiac activity for assessing stress and welfare in farm animals - a review. Physiol Behav 92: 293-316. https://doi.org/10.1016/j.physbeh.2007.01.007

Wang Y, Nickel B, Rutishauser M, Bryce C, Williams T, Elkaim G, Wilmers C (2015) Movement, resting, and attack behaviors of wild pumas are revealed by tri-axial accelerometer measurements. Mov Ecol 3:1-12. https://doi.org/10.1186/s40462-015-0030-0

Watanabe S, Sato K, Ponganis PJ (2012) Activity time budget during foraging trips of emperor penguins. PLoS One 7:e50357. https:// doi.org/10.1371/journal.pone.0050357

Weitzman J, den Heyer C, Bowen DW (2017) Factors influencing and consequences of breeding dispersal and habitat choice in female grey seals (Halichoerus grypus) on Sable Island, Nova Scotia. Oecologia 183:367378. https://doi.org/10.1007/s00442-016-3764-5

Williams TM, Fuiman LA, Horning M, Davis RW (2004) The cost of foraging by a marine predator, the Weddell seal Leptonychotes weddellii: pricing by the stroke. J Exp Biol 207:973-982. https:// doi.org/10.1242/jeb.00822

Wilson RP, Grundy E, Massy R et al (2014) Wild state secrets: ultrasensitive measurement of micro-movement can reveal internal processes in animals. Front Ecol Environ 12:582-587. https://doi.org/ $10.1890 / 140068$

Witter LA, Johnson CJ, Croft B, Gunn A, Gillingham MP (2012) Behavioural trade-offs in response to external stimuli: time allocation of an Arctic ungulate during varying intensities of harassment 
by parasitic flies. J Anim Ecol 81:284-295. https://doi.org/10.1111/ j.1365-2656.2011.01905.x

Woldstad S, Jenssen BM (1999) Thyroid hormones in grey seal pups (Halichoerus grypus). Comp Biochem Physiol A 122:157-162. https://doi.org/10.1016/S1095-6433(98)10160-5

Wolf JBW, Kauermann G, Trillmich F (2005) Males in the shade: habitat use and sexual segregation in the Galápagos sea lion (Zalophus californianus wollebaeki). Behav Ecol Sociobiol 59:293-302. https://doi.org/10.1007/s00265-005-0042-7
Yorzinski JL, Chisholm S, Byerley SD, Coy JR, Aziz A, Wolf JA, Gnerlich AC (2015) Artificial light pollution increases nocturnal vigilance in peahens. PeerJ 3:e1174. https://doi.org/10.7717/peerj.1174

Závorka L, Aldvén D, Näslund J, Höjesjö J, Johnsson JI (2016) Inactive trout come out at night: behavioral variation, circadian activity, and fitness in the wild. Ecology 97:2223-2231. https://doi.org/10.1002/ecy.1475

Publisher's note Springer Nature remains neutral with regard to jurisdictional claims in published maps and institutional affiliations. 